\title{
Time to develop tuberculosis and predictors of incidence among anti-retroviral therapy children on two selected hospitals at benishangule Gumuz region, North West Ethiopia: A retrospective cohort study
}

Fassikaw kebede Bizuneh ( $\square$ fassikaw123@gmail.com )

Jimma University

Tadese Tolossa Daba

Wollega University

Belayneh Mengist Mitiku

Debre Markos University

Tamrat shewano Fikretsion

Jimma University

Research Article

Keywords: Time to develop TB, HIV infected children, HAART, Ethiopia

Posted Date: March 24th, 2020

DOl: https://doi.org/10.21203/rs.3.rs-18481/v1

License: (9) This work is licensed under a Creative Commons Attribution 4.0 International License.

Read Full License 


\section{Abstract}

Background: Currently, tuberculosis (TB) incidence in peadtrics and children living with human immunedeficiency virus (HIV) is an emerging global concern. Although, the incidence of TB among adult HIV patients is exhaustively studied; the incidence of TB among children on ART is overlooked. Knowledge of the time when TB develops among children on ART could be helpful to develop time relevant intervention strategies.

Methods: This was a hospital based retrospective cohort study conducted among 429 children on ART from 2009-2018. Time to develop TB was defined as time from enrollment for ART care until development of TB among children on ART. Proportional hazard assumption was checked for each variable and no variable was found with Schoenfeld test $<0.05$. Variables with $P$-value $<0.25$ at bivariate Cox regression analysis were entered into multivariable Cox model. Multivariable Cox regression model with $95 \% \mathrm{Cl}$ and AHR was used to identify significant predictor variables to develop TB at $P<0.05$

Result: 421 children were followed for a total of 662.5 Person Years of observation (PYO). The maximum and minimum follow up time on ART was 0.37 and 4.49 years, respectively. The median age of the children on ART at enrollment was 9 years $(S D=3.36)$. The Overall incidence density of tuberculosis in HIV infected children was 9.6/ $100 \mathrm{PYOs} 95 \% \mathrm{Cl}$ (8.06-10.3). Tuberculosis occurrence among HIV infected children was significantly associated within TB history of contact $A H R=3.7,95 \% \mathrm{Cl}(2.89-7.2)$, not started on cotrimoxazole(CPT) AHR=2.4: $95 \% \mathrm{Cl}$ (1.84-4.74), incomplete vaccination $\mathrm{AHR}=2.4,95 \% \mathrm{Cl}(1.32-4.5)$, sever stunting $A H R=2.99: 95 \% \mathrm{Cl}(1.2-7.81)$, having hemoglobin $(\mathrm{Hgb}) \leq 10 \mathrm{mg} / \mathrm{dl} \mathrm{AHR}=4.02,95 \% \mathrm{Cl}$ $(2.01-8.1)$

Conclusion: More than $80 \%$ of TB incidences occurred during two years of follow up after ART started. So intensified screening of CPT\& therapeutic feeding is highly recommended for all children

\section{Introduction}

The Intricate linkage of tuberculosis(TB) with HIV infection for the past three decades become major threat and hindrance for international public health effort to achieve Millennium development goal [1]. Globally, tremendous progress has been made over the past decades in diagnosing and treating of TB and achieved $2 \%$ per year new TB incidence reductions [2]. However, in 20176.4 million new incidence cases of TB were reported [3], among this $9 \%$ ( 0.3 million) were new incidence of TB-HIV co-infections and $50 \%$ of new infection including inborn seropositive children were located in resource limited settings [4]. It is mainly due to difficulty in timely addressing prophylaxis and ART treatment gaps [5]. On the other hand, absence of sophisticated early HIV diagnosis technologies for inborn HIV infected children [6] increase early mortality by lethal opportunistic infections like TB $[7,8]$. It is one of the leading lethal opportunistic infection with 30-40\% lifetime incidence risk for HIV infected children [9, 10]. Global systemic review and meta-analysis on incidence of tuberculosis among PLWHIV in 2013 indicated, the incidence burden has variation in continental perspective [11], which is $31.25 \%$ in African countries, 
$25.06 \%$ in Latin America countries, $17.21 \%$ in Asian countries, $20.11 \%$ in European countries, and $14.84 \%$ in the USA [12]. Several studies in African countries have shown that the incidence of TB among HIV positive children ranges from 1-9.9 per 100PY [9-11, 13] with different times of immunological and pathophysiological response for tuberculosis incidence [14, 15], for instance in Uganda \& Zimbabwe it was 1.9/100 P-Y [11] and in Tanzania it was 5.2/100 P-Y [10]. According to global TB report of 2018, Ethiopia found top 17 twine TB \& HIV epidemic countries with 8.6-17/1000 new TB incident including seropositive children [3],With each year, 3900 HIV infected children develop morbidity by opportunistic infection especially by TB [15].

Childhood TB incidence rate varied in Ethiopia among different regions and health institutions [16]. For example, in Adama it was 6.03/100 P-Y [17], in Debre Markos 2.63/100P-Y [18], in Gondar 4.9/ 100 PY [19], in Northern Ethiopia 4.2 / 100 P-Y [20] and southern Ethiopia 2.6 /100 P-Y [21]. Another studies indicated predictor for TB incidence during ART follow up time were identified [17-19, 22]. Mainly, bedridden functional status [20] WHO stage $3 \& 4$, not on ,anemia [20, 23], rural residence[20], under nutrition [17] poor adherence [18]. Currently, tuberculosis incidence in peadtrics and children is an emerging and global concern due to its one of leading lethal opportunistic infection for children living with HIV [24]. Although, studies have been conducted on TB incidence among children on ART near the major cities [4] , the incidence of TB among children on ART at rural and nomadic community is incompletely described and overlooked [20,25]. In addition, information on the time when TB develops among children on ART is lacking too $[11,19]$.

\section{Methods}

\section{Study area, design and population}

We conducted a retrospective cohort study on 429 children on ART on treatment and care from January 1/2009 to December 31 /2018 at Assosa \& Pawe general hospitals in Benishangule Gumuz regions. Both hospitals are located in this regional state in North West Ethiopia. This region is one of the nine regions in Ethiopia. Assosa is the capital city of this region and it is located at a distance of $659 \mathrm{~km}$ in west of Addis Ababa and Pawe hospital is also located a distance from $565 \mathrm{~km}$ from Addis Ababa in North West direction. This region has currently 2 general and 3 primary hospitals with one regional laboratory. This two selected Hospitals are routinely diagnose and treat tuberculosis based on the clinical findings, chest x-ray, AFB and XpertTB for suspected TB patients [26] . In both general hospitals there has been given ART care service 2007 pediatric HIV/AIDS guideline [27]. Following the time of enrollment to ART care continuum, all children have started ARV at both hospitals. Among these, 238 and 191 children were on follow up and care at Assosa general hospitals and Pawe general hospitals, respectively. From the registration logbook, eight children with incomplete outcome data were excluded from the study.

\section{Sample size determination and sampling procedure}


Sample size for this study was calculated by using EPI INFO software using the following parameters. A) (a) of $5 \%$, power $80 \%, \mathrm{Z}=$ within $95 \% \mathrm{Cl}=1.96$ and $\mathrm{AHR}=2.39$ [20] (P1) $=6.6 \%$ and (P2) $=15.8 \%$ obtained 408 by adding $5 \%$ incomplete data final sample size will be 421 .Computer generated random number used for final study subject of study subject from two hospitals. Totally there existed 723 children started HAART and registered on computer SMART DATA sets of ART registration office since January $1^{\text {st }} / 2009-31^{\text {st }}$ December 2018. Assosa hospitals 407 and Pawe general hospital 316 children were treated. There for proportionally allocated to selected 421 samples from two hospitals.

\section{Assosa Hospital $\mathrm{n}_{\mathrm{i} 1}=(\mathrm{N} 2) \mathrm{n}=(\underline{421})(\underline{407})=236$}

N $\quad 723$

\section{Pawe Hospitals $\mathrm{ni}_{2}=(\underline{\mathrm{N} 2}) \underline{\mathrm{n}}=(\underline{316})(\underline{421})=185$ \\ N $\quad 723$}

First by using Unique ART number of each individual card retrieved from SMART DATA set of ART children ART office. Then by using computer generated random number 236 study participants from Assosa hospitals and 185 study participants from pawe general hospitals were recruited,

\section{Study variables}

In this study, the outcome variable was time to develop TB. Incident TB cases were only those who developed new TB (EPTB \& PTB) during the follow up period. The outcome variables ascertained if TB occurred only after started ART during ART follow up times.

Independent variables included: Age of children, sex, residence, family size, WHO clinical stage TB contact history, CD4 counts, Hgb, functional status, Isoniazid preventive therapy, Cotrimoxazoles preventive therapy, vaccination status, weight for age (under nutrition), weight -for -height (wasting) and height -for-age (stunting).

\section{Operational definitions}

Case ascertainment: The outcome variables (TB) was diagnosed based on bacteriological, molecular, histopathology and clinical methods by using ( microscope, sputum culture, chest x-ray, and Xpert or combinations) during patient presentation for TB symptoms [28].

Pulmonary tuberculosis: Pulmonary tuberculosis (PTB) refers to a case of TB involving the lung parenchyma. Military tuberculosis is also classified as pulmonary TB because there are lesions in the lungs. Extra pulmonary tuberculosis (EPTB): refers to a case of TB involving organs other than the lungs [28].Event: New occurrence of tuberculosis during ART care follows up times with study in periods Censored: HIV positive children who did not developed TB during ART follow up. 
TB history of contact: Children during ART follow up before TB incidence developed, having history of survives or contact at any time with who has active PTB patient.

Opportunistic infection: for HIV infected children during the following if any one of diseased developed registered on ART follow up form by their code $(B P=B a c t e r i a l ~ p n e u m o n i a, U L=$ oral ulcer , $Z=$ Herpes zoster, $\mathrm{PCP}=$ pneumocystis carnie pneumonia, $\mathrm{DC} / \mathrm{DA}$ - chronic $/$ acute diarrhea, $\mathrm{CT}=$ central nervous toxoplasmosis CM streptococcal meningitis [29].

CD4 :was classified as below the threshold according to the following age-specific thresholds: less than $15 \%$ for children aged $12-35$ months, less than $10 \%$ for children aged 36-59 months or less than 100 cells/mm3 for children aged 5-15 years [20].

Seropositive: children< 15 years were confirmed diagnosed of HIV / AIDS and under follow up.

Stunting, underweight, and wasting: The child being 2 standard deviations (SDs) below the normal for height for age, weight for age, or weight for height, according to the WHO 2006 curve. For children under or equal age 2 , wasting was measured by weight for length Z-score; for children above age 2 , wasting was defined by Z-score. Z-score $\geq-2$ was defined as non-wasting; $-3 \leq Z$-score $\leq-2$ was defined as moderate wasting; Z-score $\leq-3$ was defined as severe wasting. Stunting was measured by height/length for age Z-score. Z-score $\geq-2$ was defined as non-stunting; $-3 \leq Z$-score $\leq-2$ was defined as moderate stunting; $Z$-score $\leq-3$ was defined as severe stunting $[10,17,22]$.

\section{Data collection tools, procedures, and quality control}

Four bachelor nurses and two supervisors were selected for data collection processes and all had took ART training. For quality of data collection process, one-day traing was given in two hospitals with two supervisors for data collectors. The principal investigator and two supervisor followed data. Data were collected using the data abstraction tool and medical history sheet prepared from Ethiopian Federal ministry of health HIV/AIDS follow up forms [15].

\section{Data processing and analysis}

Data entered into the computer using EPI-DATA version 3.1 \& exported to STATA 14.1 for cleaning and analysis. Descriptive analysis, such as tables, graphs, Kaplan Meier survival curve and log rank test was done. Hazard ratio with $95 \% \mathrm{Cl} \& \mathrm{P} \leq 0.05$ was used to measure association with independent variable. The overall survival graph and hazard failure estimated curve was used to show survival and hazed probability of risk group. Cox-regression model was fitted to identify predictors for incidence of pulmonary tuberculosis. All predictors that was associated with the outcome variables in the bivariable analysis at a hazard ratio of P-value 0.25 or lower was included in multi variable Cox-regression model. Variables with adjusted hazard ratio in multivariable Cox-regression with their corresponding $95 \%$ confidence interval with P-value $<0.05$ was considered as significant predictors .Cox-proportional hazard assumption was checked by (log-log plot) \& expected versus observed Kaplan Meier graph test for each variable with schoenfield residuals test for each variable. No variables less than $<0.05$. After multivariable 
cox regression was built by transforming from bivariable $\mathrm{P}<0.25$, for finally model selection was selected by AIC \& BIC criteria [30].Finally, model adequacy was checked by Nelson Alana and Cox Snell residual combination was used for checked model adequacy \& it became on straight line with Zero origin in $\mathrm{X}$ and $\mathrm{Y}$ axis.

\section{Results}

\section{Demographic and clinical characteristic of study participants}

From 429-study participant 421 were included for final analysis and 8 cards were discarded due to incompleteness. The median age of children during this time was 9 years $(S D=3.66)$. Majority $(39.5 \%)$ of children was found at the age of group of 6-10 years. slightly more than half $(51.54 \%)$ of children were female in sex and $52 \%$ of children were live in rural residence. Nearly two third (62.5\%) of study participants were addressed isoniazid and majority of $(56.06 \%)$ children lived with their family. From the total study participants 126 children develop opportunistic infection. The most common opportunistic infection was bacterial Pneumonia 53(35.9\%) \& PCP 27(21.6\%). More than two third of children (63.9\%) found WHO clinical stage $3 \& 4$. Among total study participant $147(34.92 \%)$ has hemoglobin $\leq 10 \mathrm{mg} / \mathrm{dl}$. Among 421 children, 231(54.87\%) participant lived in 3-4 family groups. Among the total study participants more than two-third were 276 (66.27\%) were completed their vaccinating (Figure 1).On the same way among the total study participants, 113(26.84\%) HIV infected children developed CD4 count below threshold level similarly 338(80.24\%) children has appropriate developmental progression. Among the total study participants, 56(13.4\%) has poor ART adherence. During the follow up times from 421 total study participants $199(47.8 \%)$ has on children cohort of follow up, $20(4.75 \%)$ drop totally from the follow up [Table 1].

\section{Baseline Nutritional status of HIV infected children}

From the total 421 study participant, 33 (7.84 \%) children developed sever stunting (HFA<-3 Z score), also $72(17.10 \%)$ study participant developed moderate wasting (HFA) between -3- -2 Z score finally 313 (74.35 \%) HIV infected children remain above >-2 Z score.

\section{Tuberculosis incidences rate}

At the end of the follow up periods, 667.7 Person Years (PYOs) of observation was obtained. During this time 64 new TB incidences occurred. Among this 28 were found pulmonary tuberculosis and 33 were EPTB. The cumulative incidence rate 64 TB case found (15.64\%) occurred. Totally, 64-event alone took 88.2 PYOs of observation taking during follow up before event occurrence. The overall incidence density of tuberculosis among HIV infected children was 9.6 person/100 years $95 \% \mathrm{Cl}(8.06-10.3)$

\section{Survival status of HIV infected children}

Three hundred fifty-seven (84.79\%) observation was censored at the end of the follow up times. 
[Table2]. During this time 556.8 Person- years of risk, time was observed with minimum and maximum of 0.39 and 4.5 years of observation obtained respectively (Figure 2).

\section{Predictors of tuberculosis}

During bivariables analysis totally 16 variables were selected in the first steps of model building and 10 variable selected, as the best model by comparing log likely hood ratio, which include (age, isoniazid preventive therapy, Cotrimoxazole preventive therapy, TB history of contact, vaccination status, HT/WT, who clinical stage, CD4 count, Hemoglobin, adherence) involved in multivariable analysis. Five of among predictors, TB history of contact, not started on cotrimoxazole. Incomplete vaccination, sever stunting, having Hemoglobin $\leq 10 \mathrm{mg} / \mathrm{dl}$ were found have statically significant with outcome variables [Figure3 ].Based on this, the risks of developing TB among HIV infected children for not started cortimoxazole is 2.4 times increase as compared with taking cotrimoxazole (AHR $=2.4: 95 \% \mathrm{Cl}, 1.84-4.74$ ) [Table 3].

The risks of developing TB among HIV infected children having previous TB history of contact is 3.8 times increased as compared with no previous TB history of contact (AHR=3.8: 95\% Cl, 2.89-7.2). Moreover, HIV infected children didn't vaccinate in their life time has higher risks of developing TB. The risks of developing TB among HIV infected children having incomplete vaccination was 2.4 times increase as compared with completed vaccination during their life time (AHR=2.4: $95 \% \mathrm{Cl}, 1.32-4.5)$. The risks of developing TB among HIV infected children having Sever stunting 2.99 times increase as compared with HIV infected children having normal height for their age (AHR $=2.99: 95 \% \mathrm{Cl}, 1.2-7.81)$. The risks of developing TB among HIV infected children having Hemoglobin $\leq 10 \mathrm{mg} / \mathrm{dl}$ times increase as Compared with hemoglobin $\geq 10 \mathrm{mg} / \mathrm{dl}$ (AHR $=4.02: 95 \% \mathrm{Cl}, 2.01-8.1)$. Model adequacy of this multivariable cox regression was checked by Nelson Alan and Cox Snell residual combination test. ( Figure4).

\section{Discussion}

To succeed WHO 2030 "End TB epidemic " strategies there must be collaborative working of TB program with HIV /AIDS patients to address sufficient prophylaxis and ART gap [3]. Accordingly, the finding of this study indicated that the overall incidence of tuberculosis in HIV infected children was found 9.6/ 100 PYOs, 95\% Cl (8.06 -10.39). This in not comparable with study finding in southern Ethiopia 2.6/ 100 PYOs[21], Debre Markos 2.63 /100 PYOs [18] ,Northern Ethiopia 4.2/ 100 PYOs [20], Gonder 4.9/ 100 PYOs [19], Adama 6.03 /100 PYOs [17]. This might be due to higher burden of tuberculosis in resource limited settings for early diagnosis and intervention[26]. The study finding in South Africa indicate that the incidence of TB in HIV children is as higher as 21.1/ 100PYO [9]. This might be due to south Africa was classified as twine TB/HIV epidemic incidence site [31, 32]. As time goes, incidence of TB in some settings lower been observed in recent times[20].According to the finding, this study HIV infected children not started cotrimoxazoles during their follow up time was independently associated with incidence of TB as compared with taking cotrimoxazole. This is in line with north Ethiopia [20] Adama referral hospitals[17].In fact it might be due to Cotrimoxazoles preventive therapy significantly reduces HIV 
related morbidity and mortality of lethal infections [3]. On the same way, this study finding also showed that HIV infected children having previous TB history of contact is independently associated with incidence of TB as compared with non-TB contact children. This is in line with the study finding in south Africa[9].In fact low educational status and lack of awareness about transmission of pulmonary TB might easily acquire the infection from chronic carrier of nearby patients[33].

The finding of this this study indicated among HIV infected children having incomplete vaccination has independently associated with the risks of developing TB as compared with children complete their vaccination. This is comparable with the study finding in Adama referral hospitals [17] and university of Gonder [19]. The finding of this research also indicated that HIV infected children having sever stunting was independently associated with incidence of TB as compared with HIV infected children has no stunting. This in line with the study finding in Adama [17],Tanzania[10], Uganda \& Zimbabwe [11]. This might be due to HIV infection increases nutrient mal-absorption due to metabolic alterations that culminate in weight loss and stunting with time leads early exposed for opportunistic infections [29]. Similarly existence of rapid viral replication consumed body energy and create arena for incidence of TB $[2,34]$.This study finding also showed that children having hemoglobin $\leq 10 \mathrm{mg} / \mathrm{dl}$ was independently associated with TB incidence as compared with HIV infected children having hemoglobin level $>10 \mathrm{mg} / \mathrm{dl}$. This is in line with the study finding in Adama hospitals [17],university of Gonder referral hospitals [19] ,Northern Ethiopia[20], Dar es Salaam, Tanzania[10], in England and wales[23]. In fact this is due to hemoglobin levels had high predictive value for incident TB and death. TB incidence is directly associated with severe anemia [35]. Regardless of ART moderate or severe anemia during ART follow up can be independent predictor for TB $[35,36]$.

\section{Limitation of the study}

Retrospective nature of this study is one of the limitations of this study .due to this some of clinical important predictor variable which has independently associated with incidence of TB occurrence in other studies like educational status of children, economic status of family were not included in these study.

\section{Conclusion}

Incidence of TB was an important medical problem for children living with HIV ART treated in both Hospitals. This study finding concluded that baseline not ever taking cotrimoxazoles, ,having moderate stunting ,hemoglobin level lower than standard, incomplete vaccination, having previous history of contact with TB has significantly and independently associated TB incidence. So intensified screening of cotrimoxazoles and malnutrition was highly recommended for intervention.

\section{Abbreviations}

AHR: Adjusted Hazard Ratio, WFH: Weight for Height, WFA: Weight for Age, HFA: Height for Age, PYOs: Person Years of Observations, Cl: confidence interval, 


\section{Declarations}

\section{Ethical approval}

Ethical approval was first obtained from Ethical review Committee of College of medicine and Health Sciences department of public health in Debre Markos University. First formal letter was written from the university ethical board to Assosa and Pawe General Hospitals for data collection permission .After accepting and giving permission for collections of data by administrative staff in two general hospitals formal letter was written based on our request for work in ART peadtrics ward to conduct the study. Finally, individual consent from the study participates by their formal signature and a few of them by thumb finger to keep their confidentiality.

\section{Consent for publications}

No consent for publications

Availability of supporting data

All the datasets analyzed for this study is/are available in the corresponding author and can send based on reasonable request.

\section{Competing interests}

The authors declare that there are no competing interests.

Funding:

All funding of this original research process was covered by FK

\section{Author's contributions}

FKB has developed designing study, training data collectors, supervising the data collectors

TSF has worked on data cleaning, editing, entering, result writing,

TTD has participated on result interpretation

BM has participated on manuscript writing.

Acknowledgment

I would like to thanks Pawe and Assosa general hospitals administrative staffs and data collectors assisting during data collection

\section{Author information}


Both FK and TS found in Epidemiology department, faculty of public health, institute of health science, Jimma University P.O. Box: 378 Jimma Ethiopia and serves as senior lectures. TTD is working in Wollega University Institution of health science, Faculty of Public health, Department of Epidemiology, Wollega, Ethiopia. BMM currently working in Debre Markos Univecity College of Medicine and health Sciences, Department of public health, Debre Markos, Ethiopia.

\section{References}

1. Getahun H, Gunneberg C, Granich R, Nunn P: HIV infection-associated tuberculosis: the epidemiology and the response. Clinical infectious diseases : an official publication of the Infectious Diseases Society of America 2010, 50 Suppl 3:S201-207.

2. WorldHealthOrganizations.: Antiretroviral therapy for HIV infection in infants and children: towards universal access. revisedmanau/ 2010 WHO Library Cataloguing-in-Publication Data(ISBN 978924 $1599801)$.

3. WHO: Global TB report, WHO genava 2018. 2018, 227.

4. Ausman Ahmed DM, Atsede M Shiferaw, Fanuel Belayneh, Yenit MK: Incidence and determinants of tuberculosis infection among adult patients with HIV attending HIV care in north-east Ethiopia: a retrospective cohort study. BMJ 2018 V.8:e(doi:10.1136/).

5. Minaleshewa Biruk BA, 3, Senafekesh Biruk aFZA: Treatment Outcomes of Tuberculosis and Associated Factors in an Ethiopian University Hospital. Hindawi 2016, Volume 2016, Article ID 8504629, 9 pages $9,2$.

6. UNAIDS: State of HIV epidemic repeort by UNAIDS report 2018.

7. Li N, Manji KP, Spiegelman D, Muya A, Mwiru RS: Incident tuberculosis and risk factors among HIVinfected children in Tanzania. AIDS (London, England) 01 May 2013, 27(8):1273-1281 27(www.ncbi.nlm.nih.gov PMC4742782):29.

8. Jahromi K, Sharifi-Mood B: Pulmonary Tuberculosis in Children. Int J Infect 2014, 1(DOI : 10.17795/iji-21116):e21116.

9. N. A. Martinson H. Moultri RvNGB, A. Coovadiaß, M. Cottonฯ, A., Violari^ GEGEC, J. A. Mclntyre*, and T. Meyersł: HAART and Risk of tuberculosis in HIV-infected South African children: a multi-site retrospective cohort. International Journal ofTuberc and Lung Disuberc Lung Diseas 2009 13(7): 862-867(HHS Author Manuscripts PMC6374123).

10. Nan LI KPM, Donna SPIEGELMAN,: Incident tuberculosis and risk factors among HIV-infected children in Dar es Salaam, Tanzania. 2016.

11. Angela M. Crook A. Anna Turkova VM, Mutsa Bwakura-Dangarembizi Sabrina Bakeera-Kitaka, et.al. PN-N: Tuberculosis incidence is high in HIV-infected African children but is reduced by co-trimoxazole and time on antiretroviral therapy. BMC Medicine 2016, 14(DOI 10.1186/s12916-016-0593-7): 2 of 11. 
12. Junling Gao PZ, Hua Fu: Prevalence of TB/HIV co-infection in countries except China: a systematic review and meta-analysis. PloS one 2013, 8.

13. Badri M, Wilson D, Wood R: Effect of highly active antiretroviral therapy on incidence of tuberculosis in South Africa: a cohort study. The Lancet 2002, 359(9323):2059-2064.

14. Varaineb MMLLPPFFV, Daniel B: Tuberculosis after HAART initiation in HIV-positive patients from five countries with a high tuberculosis burden. CONCISE COMMUNICATION2006, AIDS 2006, Vol 20 No 9(ISSN 0269-9370 Q 2006 Lippincott Williams \& Wilkins):5.

15. FMOH: National guidelines for comprehensive HIV prevention, care and treatment. Manua/2014 https://aidsfree.usaid.gov/sites/default/files/ethiopia_natl_gl_2014.pdf:145.

16. EHNRI: ETHIOPIAN National TB/HIV ONE YEAR Sentinel Surveillance (July 2011 - June 2012). Reports 2013, .www.ennonline.net.

17. MasinoTessuBeshir AHB, Kenean Getaneh Tlaye, Tefera Mulugeta Demelew: Incidence and predictors of tuberculosis among HIV-positive children at Adama Referral Hospital and Medical College, Oromia, Ethiopia: a retrospective follow-up study. Epidemiology and Health 2019, 41(https://doi.org/10.4178/epih.e2019028):8.

18. N. EAHET: Incidence of tuberculosis in children on antiretroviral therapy: a retrospective cohort study. BMC research notes 2018, 11:https://doi.org/10.1186/s13104-13018-13846.

19. GebeyawSA. AddisK AK: Incidence and Predictors of Tuberculosis among HIV PositiveChildren at University of Gondar Referral Hospital, Northwest Ethiopia: A Retrospective Follow-Up Study. Hindawi 2015, Volume 2015, Article ID 307810, 6 pages(http://dx.doi.org/10.1155/2015/307810):Volume 2015, Article ID 307810, 307816 pages.

20. Yihun Mulugeta Alemu GA, Ejigu Gebeye.: High Incidence of Tuberculosis in the Preventive Therapy in Children Living with HIV in Northern Ethiopia: A Retrospective Follow-Up Study. PLoS ONE 11(4) 2016, PLoS ONE 11(4):e0152941( DOI:10.1371/journal.pone.0152941):10.

21. Yirdaw KD, Jerene D, Gashu Z, Edginton ME, Kumar AM, Letamo Y, Feleke B, Teklu AM, Zewdu S, Weiss $B$ et al: Beneficial effect of isoniazid preventive therapy and antiretroviral therapy on the incidence of tuberculosis in people living with HIV in Ethiopia. PloS one 2014, 9(8):e104557.

22. MuW.ZhaoY.SunX.Ma YY, L.Liu, X.Zhao, D.Dou, Z.Fang H.Zhang,: Incidence and associated factors of pulmonary tuberculosis in HIV-infected children after highly active antiretroviral therapy (HAART) in China: a retrospective study. AIDS care 2014, 26(http://dx.doi.org/10.1080/09540121.2014.882492):1127-1135.

23. A. T. Brennan RB, * K. Schnippel,§ R. Berhanu,§ M. Maskew, † L.: Incident tuberculosis in HIV-positive children, adolescents andadults on antiretroviral therapy in South Africa. INT J TUBERC LUNG DIS 20(8):1040-1045 2016, INT J TUBERC LUNG DIS 20(8):10401045(http://dx.doi.org/10.5588/ijtld.15.0488).

24. Sudjaritruk T, Maleesatharn A, Prasitsuebsai W, Lumbiganon P, Kumarasamy N, Kurniati: Prevalence, characteristics, management, and outcome of pulmonary tuberculosis in HIV-infected children in the 
TREAT Asia pediatric HIV Observational Database (TApHOD). AIDS patient care and STDs 2013, 27(12):649-656.

25. Tavitiya Sudjaritruk Alan Maleesatharn Wasana Prasitsuebsai, Siew Moy Fong NOL: Prevalence, Characteristics, Management, and Outcome of Pulmonary Tuberculosis in HIV-Infected Children inthe TREAT Asia Pediatric HIV ObservationalDatabase (TApHOD). CLINICAL AND EPIDEMIOLOGIC RESEARCH 2013, Volume 27, Number 12, (DOI: 10.1089/apc.2013.0236).

26. Haimanot Disassa KTT, Adane Worku,: A Preliminary Study on Molecular Characterization of Mycobacterium tuberculosis in Benishangul Gumuz Region, Western Ethiopia. British Microbiology Research Journal 2015.

27. FMOH : Guidelines for Paediatric HIV/AIDS Care and Treatment in Ethiopia. Guidelines 2007, https://apps.who.int/medicinedocs/en/m/abstract/Js19145en/.

28. FMOH: Guidelines for clinical and programmatic management of TB, leprosy and TB/HIV in ethiopia. guideline 2012.

29. FMOH: NATIONAL GUIDELINES FOR COMPREHENSIVE HIV PREVENTION, CARE AND TREATMENT. GUIDELINE 2017.

30. M.ail KK, J.M. Samet,Tsiatis,Wong,David Kleinbaum and Mitch Klein: Statistics for Biology and Health for survival analysis self learning book 2012.

31. WHO: Global tuberculosis control Geneve: WHO. REPORT 2015, 20th (ISBN 978924156505 9).

32. Organization.. WH: GLOBAL TB REPORT OF 2013. 2013.

33. A.Magadi2 Pga: Socioeconomic Status and Vulnerability to HIV Infection in Uganda: Evidence from Multilevel Modelling of AIDS Indicator Survey Data. AIDS research and treatment 2018, 20(https://doi.org/10.1155/2018/7812146):20.

34. Jorge OAlarcoClaudete AA, Laura Freimanis-Hance, Margot Krauss, Mary F. Reyes, jo Cardoso MMMP: Opportunistic and Other Infections in HIV-Infected Children in Latin America Compared to a Similar Cohort in the United States. AIDS RESEARCH AND HUMAN RETROVIRUSES 2011, Volume 28, Number 3, 2012(DOI: 10.1089/aid.2011.0057).

35. Amanda Mocrofta OK, Simon E. Bartonc, Manfred Dietrichd, Rui Proencae: Anaemia is an independent predictive marker forclinical prognosis in HIV-infected patients fromacross Europe. Anaemia and clinical prognosis Mocro 1999, , Vol 13 No 8(AIDS. 1999 May 28;13(8):943-50.).

36. Andrew D Kerkhoff1, 3*, Robin Wood3,4, Frank G Cobelens2,5, Ankur Gupta-Wright4, Linda-Gail Bekker3, and Stephen D Lawn3: The predictive value of current haemoglobin levels for incident tuberculosis and/or mortality during long-term antiretroviral therapy in South Africa: a cohort study. BMC Medicine (2015) 13:70 2015, DOI 10.1186/s12916-015-0320-9.

\section{Tables}

Table1: Base line socio demographic, clinical and laboratory characteristics of children on ART care at Assosa and Pawe General Hospitals since January 2009 - December 2018 EC 


\begin{tabular}{|c|c|c|}
\hline Variables & $\begin{array}{l}\text { Frequency } \\
\mathrm{N}=421\end{array}$ & $\begin{array}{l}\text { Percent } \\
100 \%\end{array}$ \\
\hline Male & 204 & 48.46 \\
\hline Female & 217 & 51.54 \\
\hline Age $<=5$ years & 87 & 20.67 \\
\hline $6-10$ & 146 & 34.39 \\
\hline$>=11$ years & 188 & 43.94 \\
\hline Residence Urban & 205 & 48.69 \\
\hline Rural & 216 & 51.31 \\
\hline Hemoglobin $>10 \mathrm{mg} / \mathrm{dl}$ & 263 & 62.92 \\
\hline$<=10 \mathrm{mg} / \mathrm{dl}$ & 158 & 37.92 \\
\hline WHO stage 1\&2 & 269 & 63.9 \\
\hline Stage $3 \% 4$ & 152 & 36.10 \\
\hline CD4 count Below threshold & 113 & 26.84 \\
\hline Above threshold & 308 & 73.16 \\
\hline Functional Appropriate & 338 & 80.24 \\
\hline Delay & 50 & 11.89 \\
\hline Regression & 31 & 7.84 \\
\hline Adherence Good & 224 & 57.96 \\
\hline Fair & 121 & 28.73 \\
\hline poor & 56 & 13.44 \\
\hline Isoniazid yes & 258 & 61.52 \\
\hline No & 163 & 38.48 \\
\hline Cotrimoxazoles yes & 321 & 76.26 \\
\hline No & 100 & 23.94 \\
\hline opportunistic infections yes & 126 & 29.93 \\
\hline No & 295 & 70.07 \\
\hline Vaccination Completed & 276 & 66.27 \\
\hline Defaulted & 76 & 18.2 \\
\hline Not registered & 69 & 16.05 \\
\hline TB contact history Yes & 135 & 32.8 \\
\hline No & 286 & 68.17 \\
\hline Family size $<=2$ & 133 & 31.83 \\
\hline $3-4$ & 219 & 52.21 \\
\hline $5-6$ & 50 & 11.88 \\
\hline$>=7$ & 19 & 4.09 \\
\hline Children status being on follow up & 199 & 47.7 \\
\hline
\end{tabular}




\begin{tabular}{|c|c|c|c|}
\hline & Lost from follow up & 43 & 10.23 \\
\hline & Transfer in to adult & 91 & 21.62 \\
\hline & Transfer out & 56 & 13.30 \\
\hline & Died & 12 & 2.85 \\
\hline & Drop & 20 & 4.75 \\
\hline \multirow[t]{2}{*}{ ART regiment } & Changed & 85 & 20.24 \\
\hline & Not changed & 336 & 79.2 \\
\hline
\end{tabular}

Table2-summary of TB free survival rate of HIV infected children at Assosa and Pawe General Hospitals since 2009-2018

\begin{tabular}{l|l|l|l|l|l|}
\hline $\begin{array}{l}\text { ime } \\
\text { ears/month }\end{array}$ & $\begin{array}{l}\text { Survival } \\
\text { rate }\end{array}$ & $95 \%$ ci & $\begin{array}{l}\text { New } \\
\text { events }\end{array}$ & $\begin{array}{l}\text { Cumulative } \\
\text { frequency }\end{array}$ & $\begin{array}{l}\text { Frequency } \\
\%\end{array}$ \\
\hline years & $96.04 \%$ & $\begin{array}{l}93.62- \\
-97.56\end{array}$ & 20 & 20 & $31.3 \%$ \\
\hline years & $82.62 \%$ & $\begin{array}{c}77.80- \\
-86.49\end{array}$ & 33 & 53 & $82.3 \%$ \\
\hline years & $77.65 \%$ & $\begin{array}{l}71.57- \\
-82.59\end{array}$ & 10 & 63 & $98.1 \%$ \\
\hline years & $68.92 \%$ & $\begin{array}{c}53.32- \\
-80.22\end{array}$ & 1 & 64 & $100 \%$ \\
\hline 5 years & $68.92 \%$ & 50.2 & 0 & 64 & $100 \%$ \\
\hline
\end{tabular}

Table3: Bivariable and multi variable cox-proportional hazard analysis for time to develop TB among children treated on ART OPD at Assosa and Pawe General Hospitals 20092018 


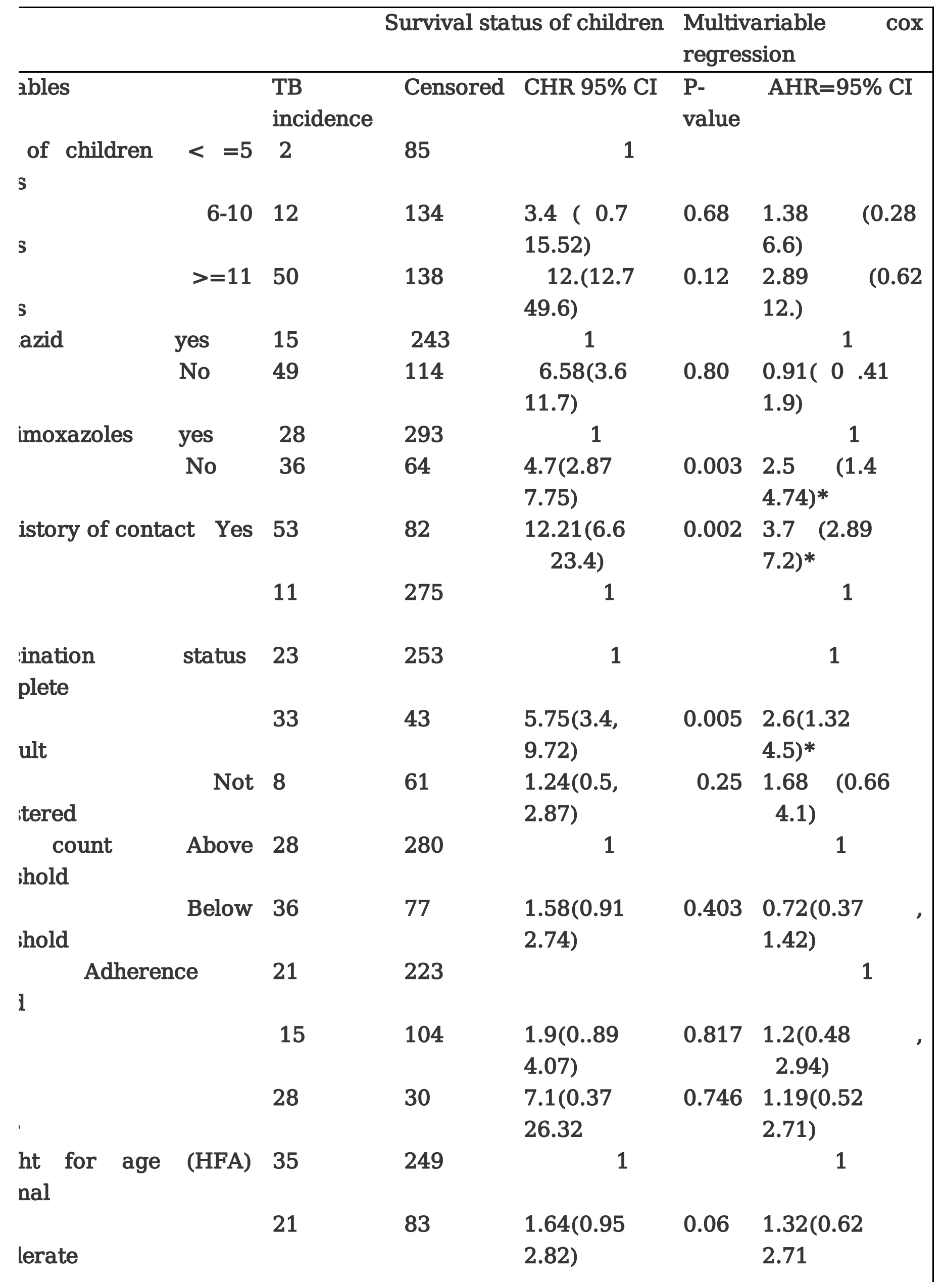




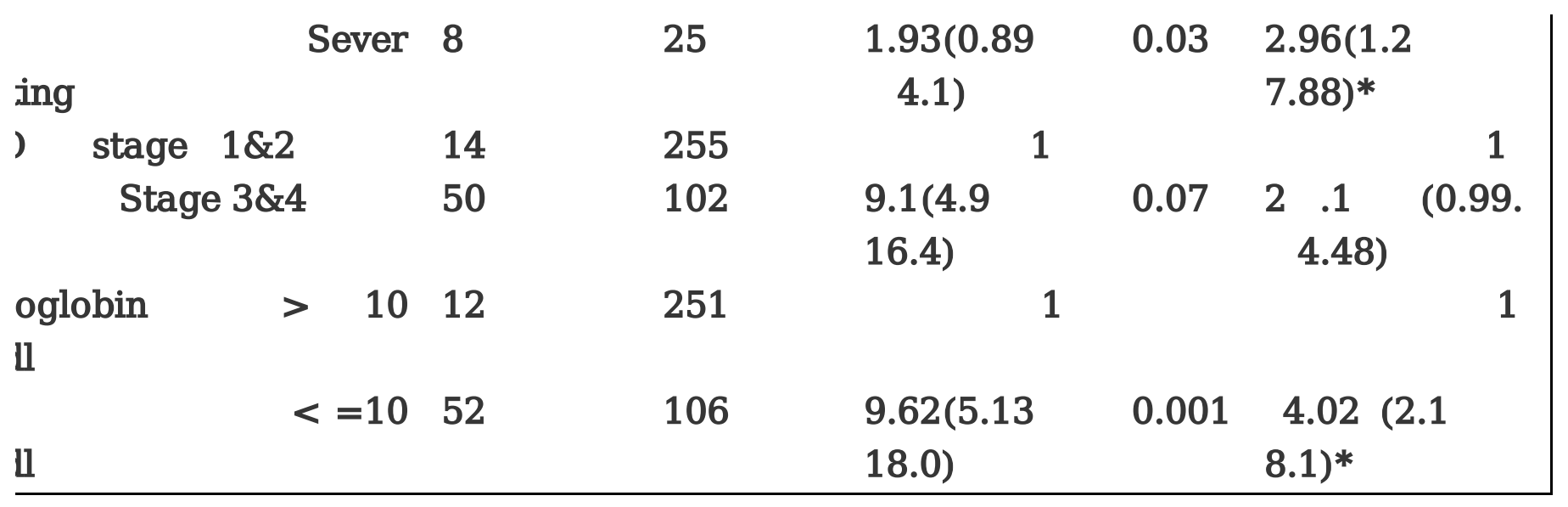

\section{Figures}

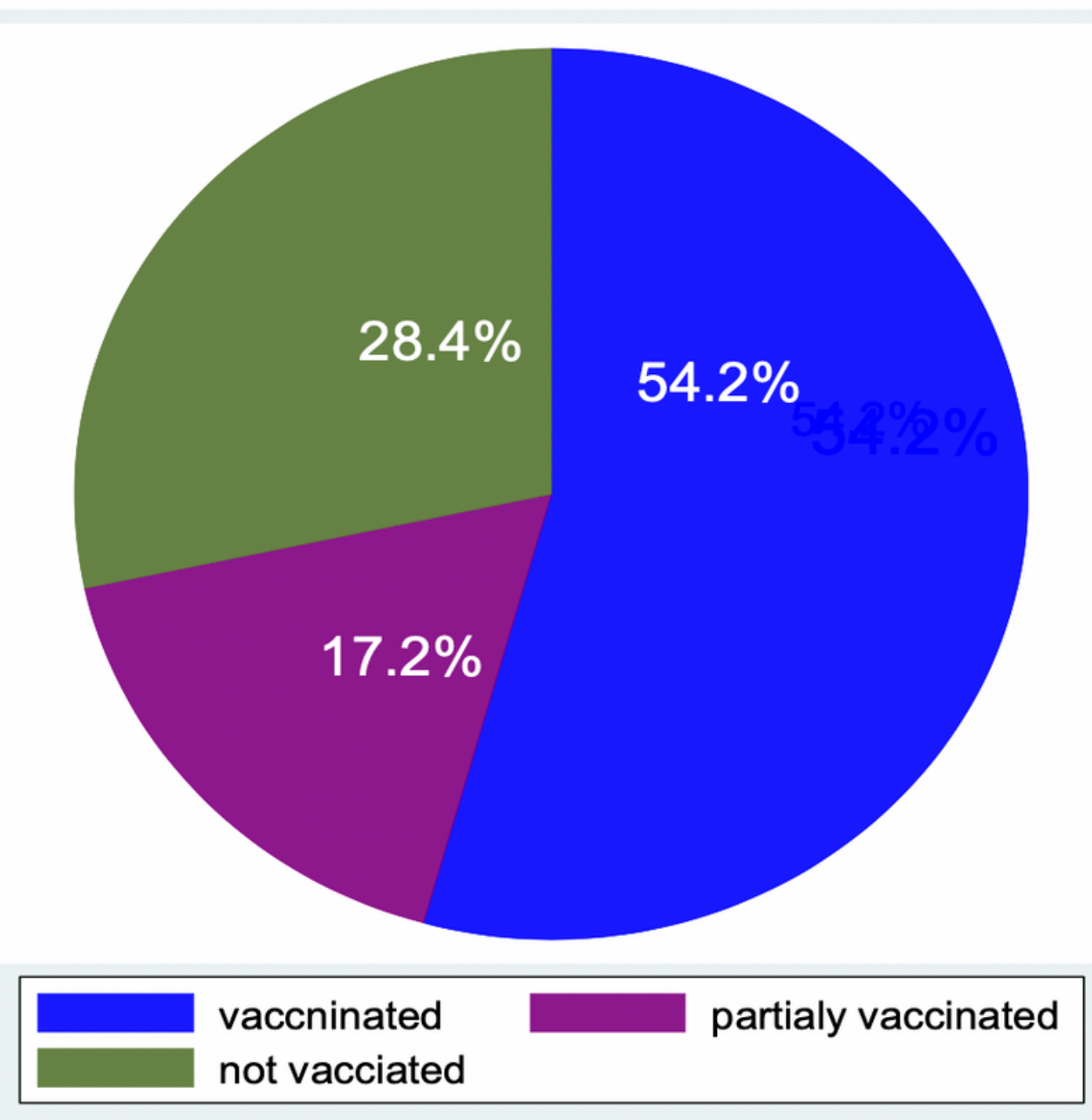

Figure 1

vaccination status of HIV infected children in Pawe General Hospital during ART follow up time since 2009-2018 


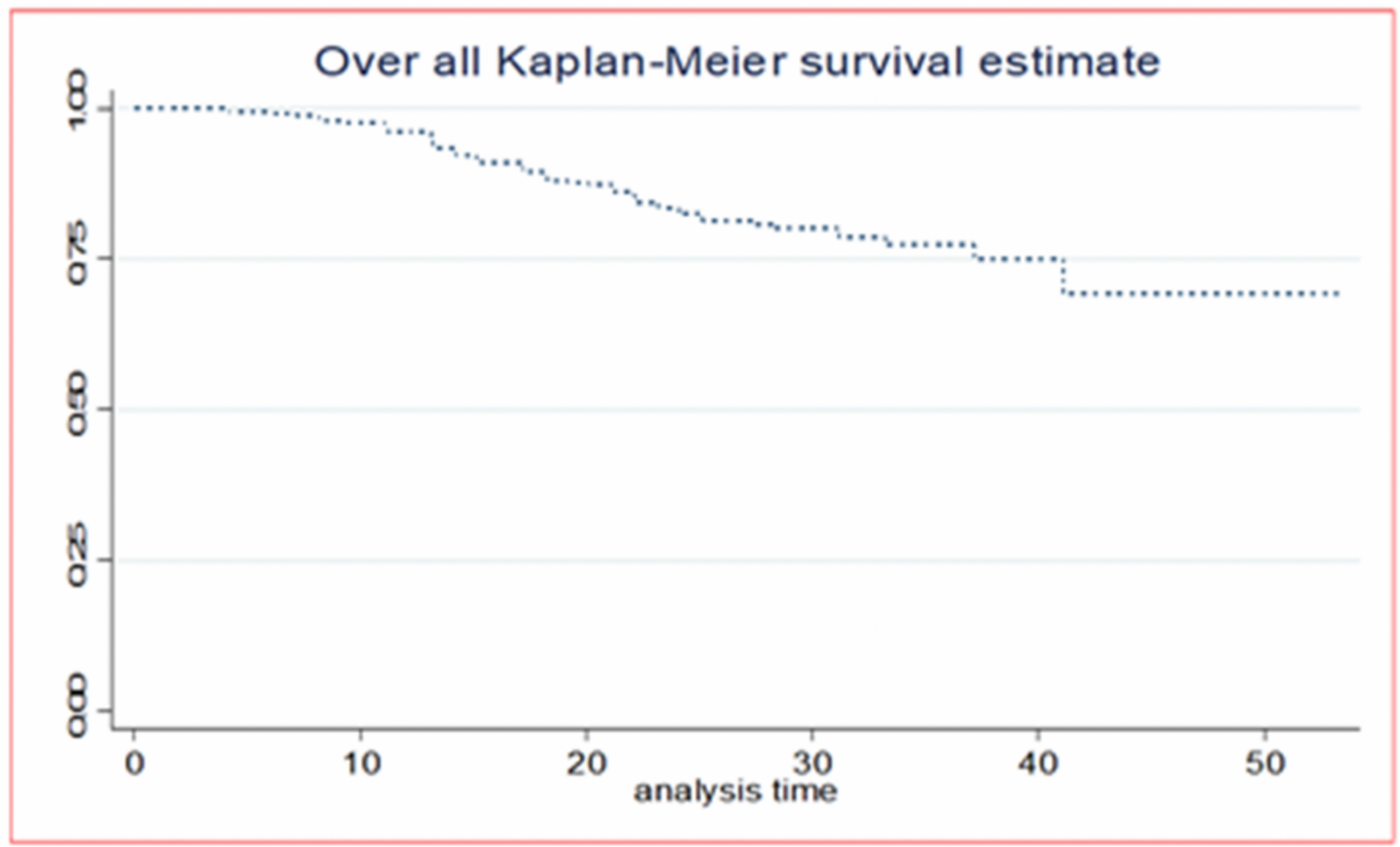

Figure 2

The overall Kaplan-Meier TB free survival probability of HIV infected children from tuberculosis incidence since 2009-2018. 


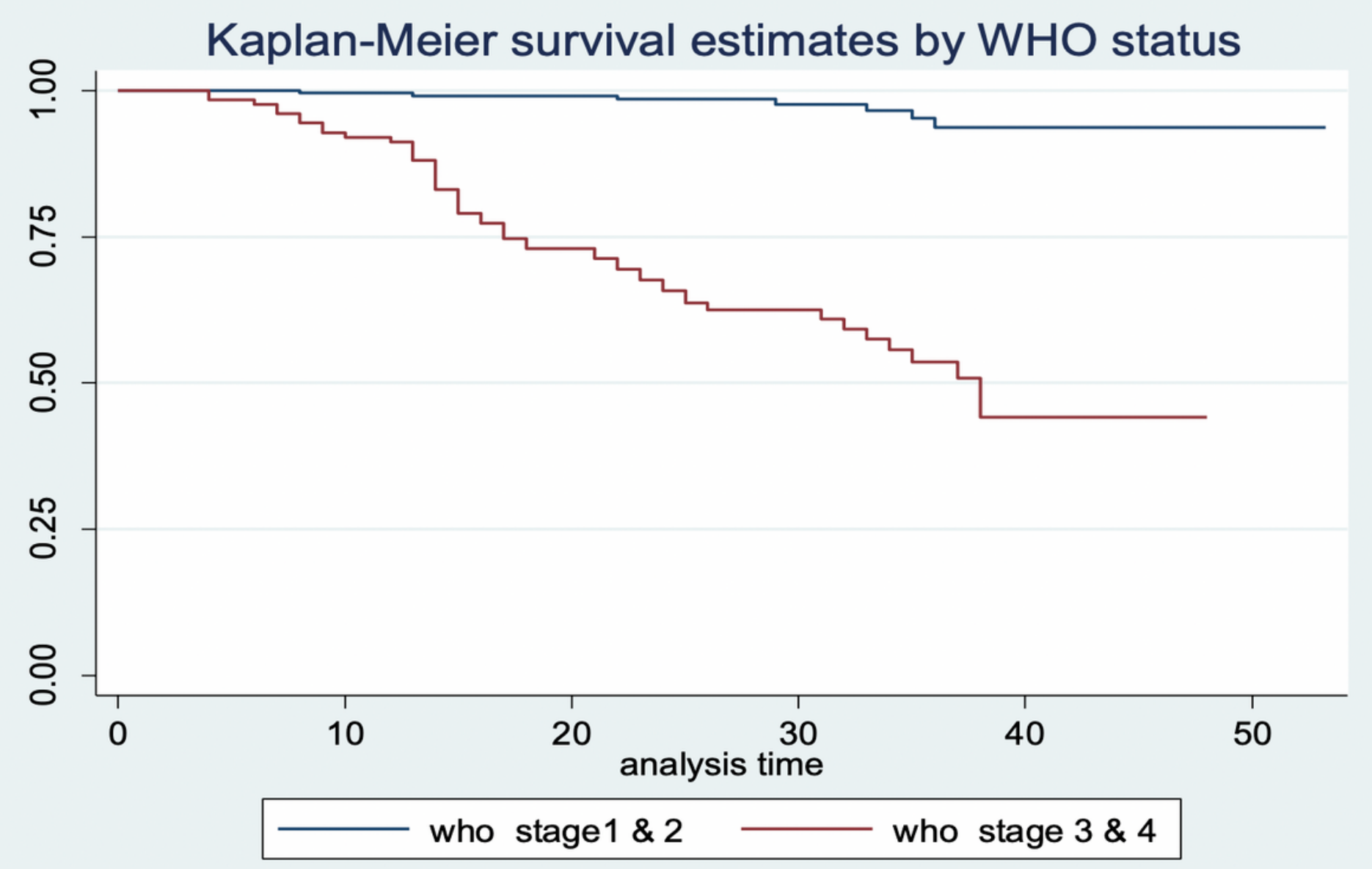

Figure 3

Kaplan Meier survival estimate based on who clinical stage stratification among HIV infected children at Assosa and Pawe general hospitals since (2009-2019.) 


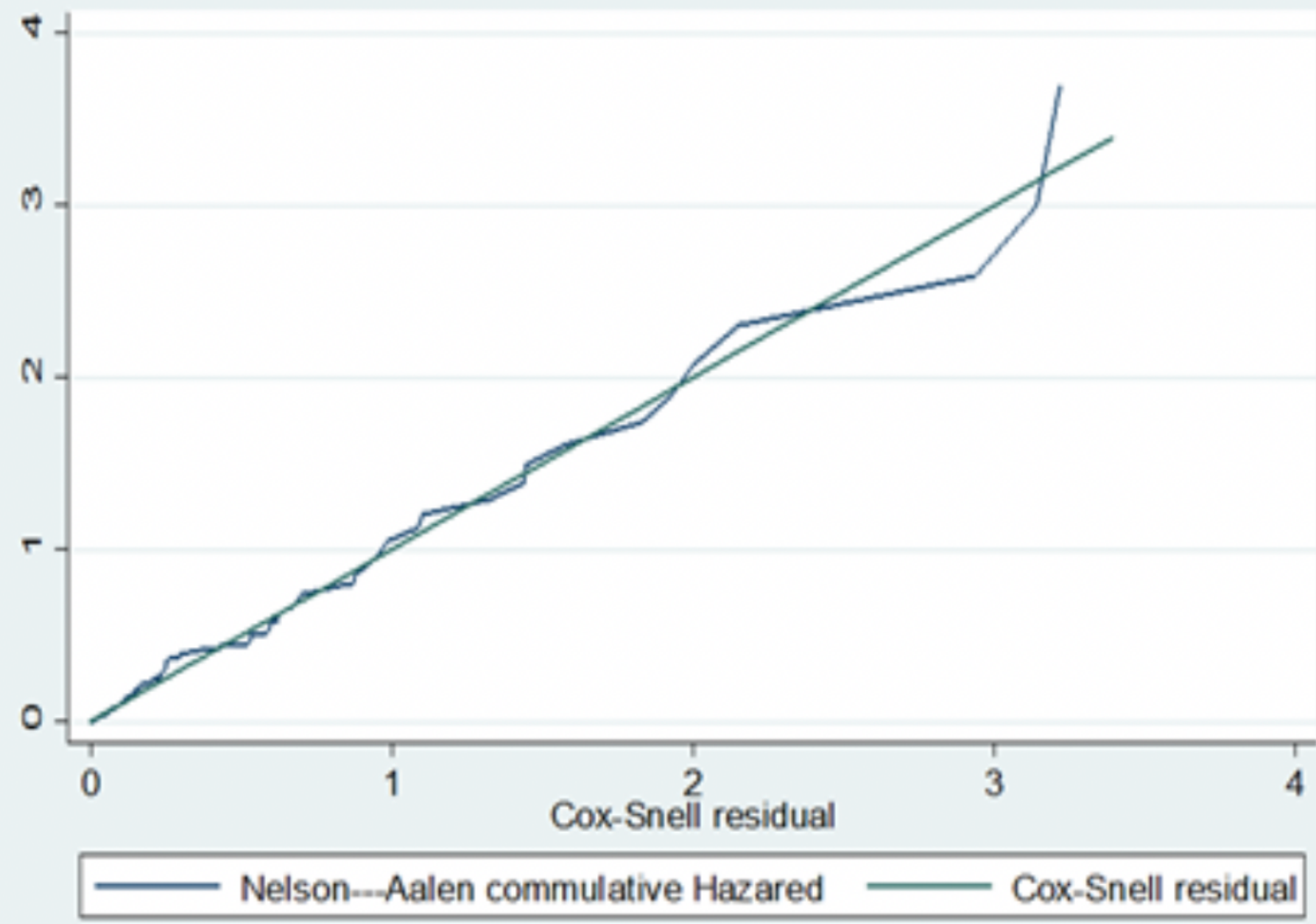

Figure 4

Model adequacy for time to develop TB among HIV infected children in Northwest Ethiopia based on by Nelson Aalen and Cox-Snell residual test. 